\title{
Enhanced Oil Recovery by Injecting Oleic Acid as a Surfactant into the Porous Medium
}

\author{
Mmadi Salim Mohamed, Sosse Ndyaye, Kharouna Talla, Cheikh Mbow, Aboubaker Chedikh Beye \\ Department of Physics, Faculty of Science and Technics, Cheikh Anta Diop University, Dakar, Senegal \\ Email: salimaxe@yahoo.fr
}

How to cite this paper: Mohamed, M.S., Ndyaye, S., Talla, K., Mbow, C. and Beye, A.C. (2020) Enhanced Oil Recovery by Injecting Oleic Acid as a Surfactant into the Porous Medium. Open Journal of Fluid Dynamics, 10, 82-94.

https://doi.org/10.4236/ojfd.2020.101006

Received: February 11, 2020

Accepted: March 22, 2020

Published: March 25, 2020

Copyright $\odot 2020$ by author(s) and Scientific Research Publishing Inc. This work is licensed under the Creative Commons Attribution International License (CC BY 4.0).

http://creativecommons.org/licenses/by/4.0/

\begin{abstract}
Physico-chemical methods of improved oil recovery make it possible to increase oil production in deposits by injecting surfactants acting on various physical parameters. Oleic acid has an effect on the viscosity of the displacement fluid and the flow rate. Therefore, increasing the viscosity of the displacement fluid plays an essential role in improving the improved oil recovery. The physicochemical properties at the interface between petroleum and water are modified by oleic acid, lowering the viscosity of petroleum and increasing the viscosity of water, which facilitated the mobility of petroleum in the porous medium.
\end{abstract}

\section{Keywords}

Porous Medium, Complex Fluids, Surfactant, Oleic Acid, Two-Phase Flows

\section{Introduction}

After the primary recovery of oil (which uses the tank pressure above atmospheric pressure as a production engine) and the secondary recovery (injection of water or gas to increase and maintain the pressure in the deposit) during which 20 at $40 \%$ of the oil initially present is extracted, the improved recovery of oil known as tertiary recovery makes it possible to extend exploitation in the oil fields and the recovery up to $30 \%$ to $60 \%$ of the oil obtained present [1] [2] [3].

Improved oil recovery techniques are more expensive than primary and secondary recovery methods, hence the choice used oleic acid as a surfactant which is cheaper and abundant in nature to improve the mobility of the flow between the fluid injected and the oil that remains trapped in the pores. Oleic acid con- 
stitutes between $55 \%$ and $80 \%$ of olive oil, and is full of all animal or vegetable oils, such as grape seed oil which represents $15 \%$ to $20 \%$, see Table 1 .

By injecting oleic acid into porous media containing water and petroleum, the volume of oil recovered increases with the concentration of oleic acid.

So we can put forward the hypothesis that the viscosity of water increases and that of petroleum decreases, which facilitates the sweeping and the transport of petroleum towards the exit.

The objective of this research work is to try to understand how to efficiently mobilize and move the trapped oil in porous media towards the outlet.

In this experimental work, the less viscous oil is displaced by water, a Newtonian fluid and by surfactants which facilitate sweeping, see Figure 1.

Table 1. Mass percentage of oleic acid of animal and vegetable origin [16] [17].

\begin{tabular}{cc}
\hline Nature & Mass percentage of oleic acid \\
\hline Olive oil & $80 \%$ \\
Nuts Oil & $77.8 \%$ \\
Avocado Oil & $67 \%$ \\
Colza Oil & $56 \%$ \\
Peanut Oil & $44.8 \%$ \\
Beef fat & $36 \%$ \\
Cocoa butter & $34 \%$ \\
Corn Oil & $27 \%$ \\
Soya Oil & $23 \%$ \\
Sheep fat & $38 \%$ \\
Palm Oil & $37 \%$ \\
\hline
\end{tabular}

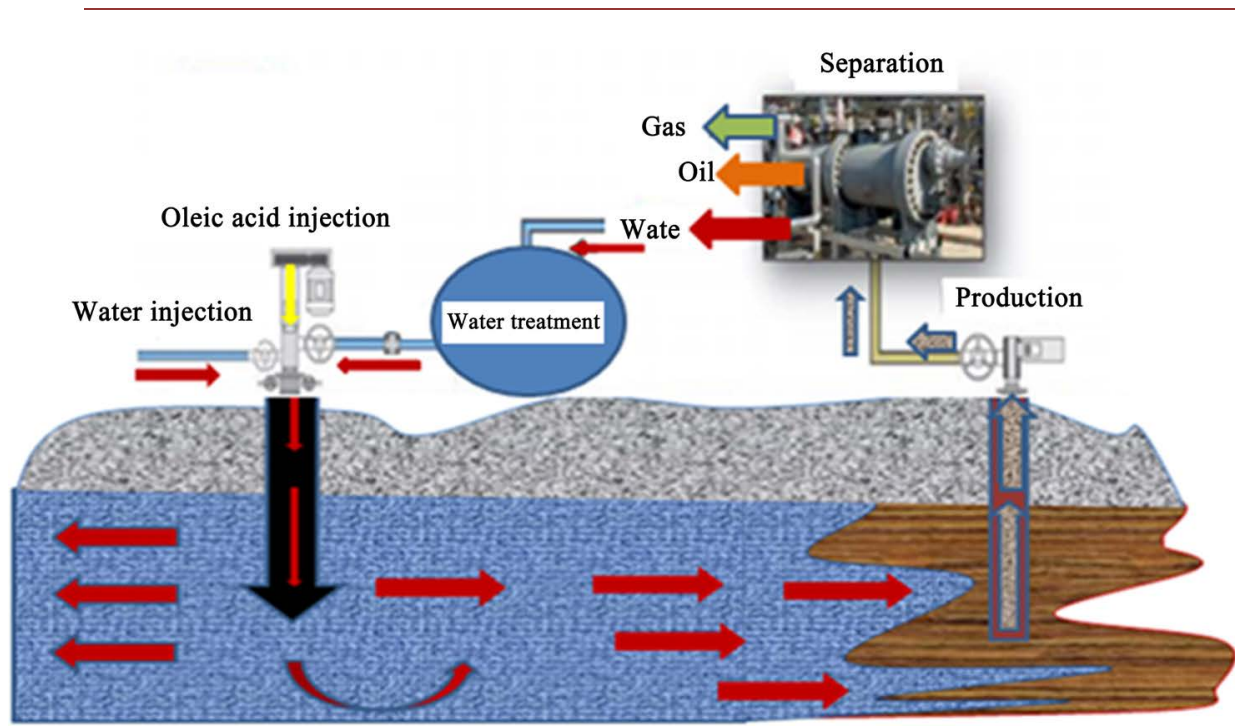

Figure 1. Enhanced recovery of petroleum by injection of water and surfactants (secondary and tertiary) [4]. 


\section{Experimental Study}

\subsection{Introduction}

The chemical composition of crude oil is complex and very variable from one oil field to another. Some are very viscous, others are corrosive and others contain sediments or paraffin crystals. This induces many constraints for their handling.

Therefore, most of the industries and laboratories involved in the formulation of surfactants for enhanced oil recovery, have chosen to work with alkaline solutions coupled with solutions of polymers and surfactants. This method has been tested in the laboratory and in oil fields and it has been shown to be effective in displacing residual oil saturation [5] [6] [7] [8]. Among the methods of enhanced oil recovery, on an injected into the porous medium saturated with petroleum, olive oil with different concentrations of oleic acid, which allows the efficiency of scanning on a macroscopic scale by increasing the viscosity of the displacing fluid. Presenting between $60 \%$ and $80 \%$ of the composition of olive oil, oleic acid makes it possible, on a microscopic scale, to reduce the permeability with respect to tank water thanks to the various mechanisms of retention of molecules, which is the case of surfactants, [9] [10] [11]. We have chosen to use oleic acid because of its abundance in nature, see Table 1.

\subsection{Oleic Acid}

Oleic acid is an amphiphilic molecule made up of two parts: a polar hydrophilic group and a non-polar hydrophobic part, see Figure 2. The polar head makes the surfactant formed from oleic acid soluble in water and polar solvents while the hydrophobic tail makes it soluble in non-polar solvents and petroleum. The relative sizes of the two groups determine a number of properties [12] [13] [14].

\subsection{Reactivity of the Carboxylic Function}

The carboxylic function - $\mathrm{COOH}$ has an acidic hydrogen (mobile hydrogen) which can react with a base like soda. A carboxylate ion -COO- is then formed.

The presence of this group increases the water solubility of this chemical species. However, the essential property of sodium oleate is to be a surfactant. The two-phase mixture of yellow oleic acid and water with soda gives a milky (white) system which lathers when stirred.

the head is hydrophilic

which turns towards water

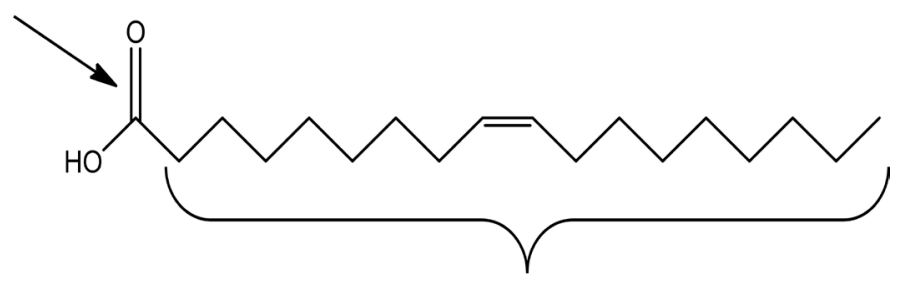

the tail hydrophobic which does not like water

Figure 2. The oleic acid used to form the surfactants [15]. 
Combined surfactants have been the most studied as models of giant micelles both in theory and in practice.

These studies have made it possible to understand the microstructure of these surfactants in the presence of different additives and their influence on enhanced oil recovery [18] [19] [20] [21].

\section{Equations and Models}

The application of Darcy's law for each phase allows us to describe two-phase flows in porous media. We use for each phase dimensionless factors $K_{0}$ and $K_{w}$ called relative phase permeabilities, which take into account the speed of flow of the two fluids.

For incompressible liquids like water and petroleum, the equations for the conservation of mass and momentum have the form:

$$
\begin{gathered}
\phi \frac{\partial s}{\partial t}+\operatorname{div}\left(\boldsymbol{v}_{0}\right)=0 \\
-\phi \frac{\partial s}{\partial t}+\operatorname{div}\left(\boldsymbol{v}_{w}\right)=0 \\
\boldsymbol{V}_{o}=-\frac{K k_{o}}{\mu_{o}} \operatorname{grad}(P) \\
\boldsymbol{V}_{\beta}=-\frac{K k_{\beta}}{\mu_{\beta}} \operatorname{grad}(P) \\
P_{w}-P_{0}=P_{c}(s)=\frac{\sigma \cos (\theta)}{\sqrt{K / \phi}} J(s)
\end{gathered}
$$

With $w$ and 0 the respective indices of the water and petroleum phases; saturation $s$ of the oil-containing phase; $\boldsymbol{v}$ the speed of flow in the porous medium; $k$ permeability, $\phi$ porosity; $\mu$ is the dynamic viscosity; $P$ is the phase pressure; $P_{c}(s)$ is the macroscopic capillary pressure; $\sigma$ is the surface tension; $\theta$ is the contact angle; $\boldsymbol{v}_{w}$ and $\boldsymbol{v}_{0}$ are respectively the filtration speeds of water and petroleum in the porous medium; $t$ is the time. Relative permeabilities $k_{0}(s), k_{w}(s)$ and the additional capillary pressure $J(s)$, which are empirical functions, depend on saturation. By intruding on the expressions of speeds $\boldsymbol{v}_{w}$ and $\boldsymbol{v}_{0}$, in relation (1), we obtain the following relations according to $s$ and for $P=P_{0}$ :

Equations (1)-(4), are valid for the flow domain before the front, where we observe the two-phase flow. However, it is possible to show that they also remain valid after the front, where only the displaced phase flows. In effect, after the front $s=0$ (or the saturation is equal to a non-zero value, but the water is motionless),

$$
\begin{gathered}
\boldsymbol{V}_{o}=0, k_{w}=1, k_{o}=0 \\
\operatorname{div}(\lambda \operatorname{grad}(P))=-\operatorname{div}\left(\lambda_{w} \operatorname{grad}\left(P_{c}\right)\right) \\
\phi \frac{\partial s}{\partial t}-\lambda \operatorname{grad}(P)+\lambda_{w} \operatorname{grad}\left(P_{c}\right) \operatorname{grad}(F)=-\operatorname{div}\left(\lambda_{w} \operatorname{Fgrad}\left(P_{c}\right)\right)
\end{gathered}
$$


With $\lambda_{0}(s)=\frac{K k_{0}(s)}{\mu_{0}} ; \lambda_{w}(s)=\frac{K k_{w}(s)}{\mu_{w}} ; \lambda=\lambda_{0}+\lambda_{w} ; F(s)=\frac{\lambda_{0}}{\lambda}$.

The function $F(s)$ is a dimensionless quantity.

In the case of one-dimensional flow, we have:

$$
\begin{gathered}
\lambda(s) \frac{\partial P}{\partial x}=-\lambda_{w}(s) \frac{\partial P_{c}}{\partial x}-U(t) \\
\lambda(s) \frac{\partial P}{\partial x}=-\lambda_{w}(s) \frac{\partial P_{c}}{\partial x}-U(t) \\
\phi \frac{\partial s}{\partial t}+U(t) \frac{\partial F(s)}{\partial x}=-\frac{\partial}{\partial t}\left(\lambda_{w}(s) F(s) \frac{\partial P_{c}(s)}{\partial x}\right)
\end{gathered}
$$

With $U(t)$ which has the sense of the total speed of the two phases between water and oil.

The relation (5) between the macroscopic capillary pressure and the pressures of water and oil, is written by analogy with the microscopic equation of Laplace for the capillary pressure on an individual meniscus.

Despite the formal analogy, this relationship is insufficiently argued and creates some difficulties which will be discussed and addressed in the next article.

Note that the degenerate models of Equations ((1), (2) and (7), (10)) have a delicate and difficult use to obtain analytical solutions. However, their digital resolutions are quite easy.

\section{Preparation of the Sample}

The porous medium used consists of sand ranging from $2 \mathrm{~mm}$ to $4 \mathrm{~mm}$ in diameter. The preparation of the samples consists in filling a plexiglass cylinder with an internal diameter equal to $95 \mathrm{~mm}$, an external diameter $100 \mathrm{~mm}$ and $50 \mathrm{~cm}$ long.

On both sides of the cylinder are mounted injectors provided with O-rings to inject the fluids at the inlet and recover the fluids displaced at the outlet.

The injectors are fitted with a valve for connection to the injection pump and pressure taps for the pressure drop measured from an acquisition computer.

Once the porous medium is saturated with light petroleum, the olive oil used as complex fluid is introduced into the porous medium at different mass concentrations of oleic acid, see Table 2.

Once the porous medium is saturated with Prut petroleum, the olive oil used as complex fluid is introduced into the porous medium by different mass concentrations of oleic acid, see Table 2.

We have three stock solutions containing $60 \%, 70 \%$ and $80 \%$ by mass of oleic acid, respectively. The solutions are prepared by diluting the stock solution in a volumetric flask.

The different olive oils used contain mass percentages of oleic acid of $60 \%$, $70 \%$ and $80 \%$ respectively. 
Table 2. Influence and comparison of the volume of oil recovered as a function of the concentration of oleic acid contained in olive oil.

\begin{tabular}{|c|c|c|c|c|}
\hline $\begin{array}{l}\text { Volume } \mathrm{Vp}(\mathrm{ml}) \text { of oil } \\
\text { displaced without the } \\
\text { injection of oleic acid }\end{array}$ & $\begin{array}{l}\text { Volume of oil } \mathrm{Vp}(\mathrm{ml}) \text { displaced } \\
\text { for an injection of olive oil } \\
\text { containing } 60 \% \text { oleic acid. }\end{array}$ & $\begin{array}{l}\text { Time } \\
(\min )\end{array}$ & $\begin{array}{c}\text { Water flow } \mathrm{q} \\
(\mathrm{ml} / \mathrm{min})\end{array}$ & $\begin{array}{c}\text { Sand diameter } \\
\mathrm{D}(\mathrm{mm})\end{array}$ \\
\hline 13.3 & 13.2 & 15 & 1.71 & $2<\mathrm{D}<4$ \\
\hline 23.8 & 26.1 & 30 & 1.71 & $2<\mathrm{D}<4$ \\
\hline 36.4 & 38.7 & 45 & 1.71 & $2<\mathrm{D}<4$ \\
\hline 49.1 & 52.6 & 60 & 1.71 & $2<\mathrm{D}<4$ \\
\hline 62.0 & 65.2 & 75 & 1.71 & $2<\mathrm{D}<4$ \\
\hline $\begin{array}{l}\text { Volume } \mathrm{Vp}(\mathrm{ml}) \text { of oil } \\
\text { displaced without the } \\
\text { injection of oleic acid }\end{array}$ & $\begin{array}{l}\text { Volume of oil } \mathrm{Vp}(\mathrm{ml}) \text { displaced } \\
\text { for an injection of olive oil } \\
\text { containing } 70 \% \text { oleic acid. }\end{array}$ & $\begin{array}{l}\text { Time } \\
(\mathrm{min})\end{array}$ & $\begin{array}{c}\text { Water flow q } \\
(\mathrm{ml} / \mathrm{min})\end{array}$ & $\begin{array}{l}\text { Sand diameter } \\
\mathrm{D}(\mathrm{mm})\end{array}$ \\
\hline 12.3 & 17.5 & 15 & 1.71 & $2<\mathrm{D}<4$ \\
\hline 23.8 & 34.2 & 30 & 1.71 & $2<\mathrm{D}<4$ \\
\hline 36.4 & 47.8 & 45 & 1.71 & $2<\mathrm{D}<4$ \\
\hline 49.1 & 59.7 & 60 & 1.71 & $2<\mathrm{D}<4$ \\
\hline 62.0 & 73.1 & 75 & 1.71 & $2<\mathrm{D}<4$ \\
\hline $\begin{array}{l}\text { Volume } \mathrm{Vp}(\mathrm{ml}) \text { of oil } \\
\text { displaced without the } \\
\text { injection of oleic acid }\end{array}$ & $\begin{array}{l}\text { Volume of oil } \mathrm{Vp}(\mathrm{ml}) \text { displaced } \\
\text { for an injection of olive oil } \\
\text { containing } 80 \% \text { oleic acid. }\end{array}$ & $\begin{array}{l}\text { Time } \\
(\min )\end{array}$ & $\begin{array}{c}\text { Water flow } \mathrm{q} \\
(\mathrm{ml} / \mathrm{min})\end{array}$ & $\begin{array}{l}\text { Sand diameter } \\
\mathrm{D}(\mathrm{mm})\end{array}$ \\
\hline 12.3 & 29.7 & 15 & 1.71 & $2<\mathrm{D}<4$ \\
\hline 23.8 & 48.2 & 30 & 1.71 & $2<\mathrm{D}<4$ \\
\hline 36.4 & 65.2 & 45 & 1.71 & $2<\mathrm{D}<4$ \\
\hline 49.1 & 85.4 & 60 & 1.71 & $2<\mathrm{D}<4$ \\
\hline 62.0 & 106.3 & 75 & 1.71 & $2<\mathrm{D}<4$ \\
\hline
\end{tabular}

\section{Experimental Protocol}

1) Saturation of the porous medium with petroleum, then with olive oil;

2) Know the information of oleic acid on the displacement of petroleum by introducing olive oil of different concentrations of oleic acid into the porous medium;

3) Determination of water permeability by measuring the pressure loss between 0 and 900 mbar using the pressure sensor;

4) impose a flow rate between 0 and $700 \mathrm{ml} / \mathrm{min}$ using the pump;

5) The measurements made are stored on a computer via an acquisition card controlled by appropriate software;

6) A fraction collector is used to collect the volume of oil displaced.

The experimental configuration illustrated in Figure 3 consists of:

The pump making it possible to impose a flow of fluid in the porous medium, of a cylindrical plexiglass tube of length $50 \mathrm{~cm}$ and internal diameter $95 \mathrm{~mm}$ containing the porous medium reconstituted to get as close as possible to the characteristics of an oil deposit, a differential pressure sensor which measures the 


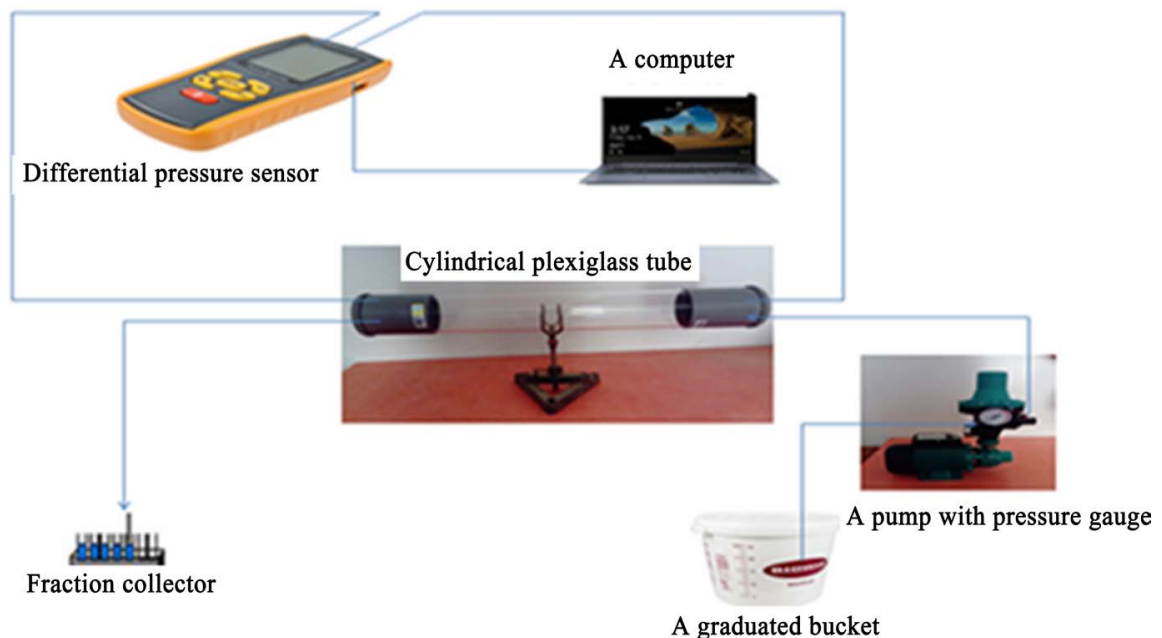

Figure 3. Experimental setup.

pressure differences between the inlet and the outlet of the porous medium over a range of 0 to 100 mbar from an acquisition computer making it possible to process the data using an acquisition card adapted to the software with ana$\log$ train and connectable by USB, a fraction collector to recover the effluents leaving the sample such as (water, petroleum, surfactants) and control the time spent filling each tube.

\section{Results and Discussion}

The improved recovery of the oil obtained by soaking the water and injecting olive oil into the porous medium saturated with petroleum is greater than that obtained only by soaking the water, which results in the spacing of the red graph obtained from experimental measurements with injection of oleic acid relative to the black graph obtained with only injection of water into the porous medium. this spacing increases with the concentration of oleic acid, see Figures 4-6.

This volume recovered by injection of the surfactants depends on the concentration of oleic acid contained in the olive oil.

This may suggest that the samples are more wettable with water in the presence of oleic acid in the porous medium, which facilitates the displacement of petroleum in the porous medium, see Table 2.

Secondary recovery with the injection of water without olive oil into the porous medium, makes it possible to recover approximately $45 \%$ of oil. During this phase, we are dealing with a piston type flow during which the oil is pushed uniformly by a water front, which could be produced in an oil deposit by displacing the trapped oil at the level of the pores and rocks to production wells.

Furthermore, the slope of the oil recovery curve in this first phase obtained without the use of surfactants corresponds well to the injection rate which is in $\mathrm{ml} / \mathrm{min}$.

For tertiary recovery, the phase of injection into the porous medium of olive oil with different mass concentrations of oleic acid makes it possible to recover $65 \%$ of the oil. Unlike secondary recovery, the rate of tertiary recovery is no longer of the piston type since we recover both water and oil. 


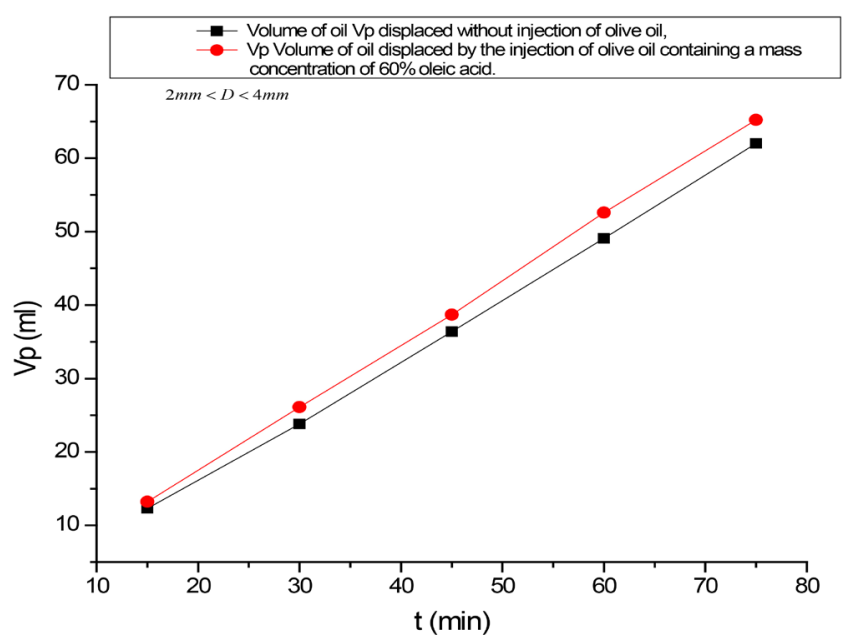

Figure 4. Vp volume of oil displaced for injection into the porous medium of olive oil containing a mass concentration of oleic acid of $60 \%$.

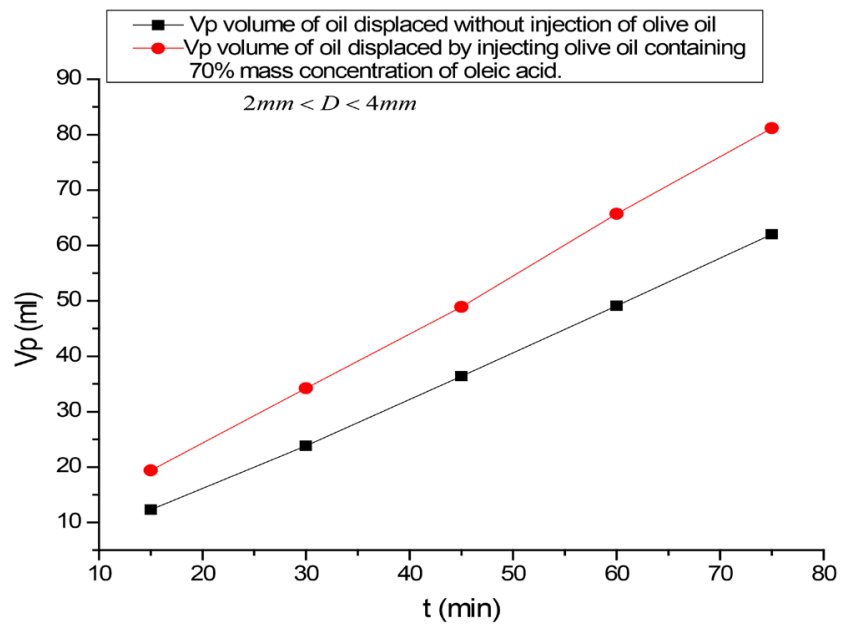

Figure 5. Vp volume of oil displaced for injection into the porous medium of olive oil containing a mass concentration of oleic acid of $70 \%$.

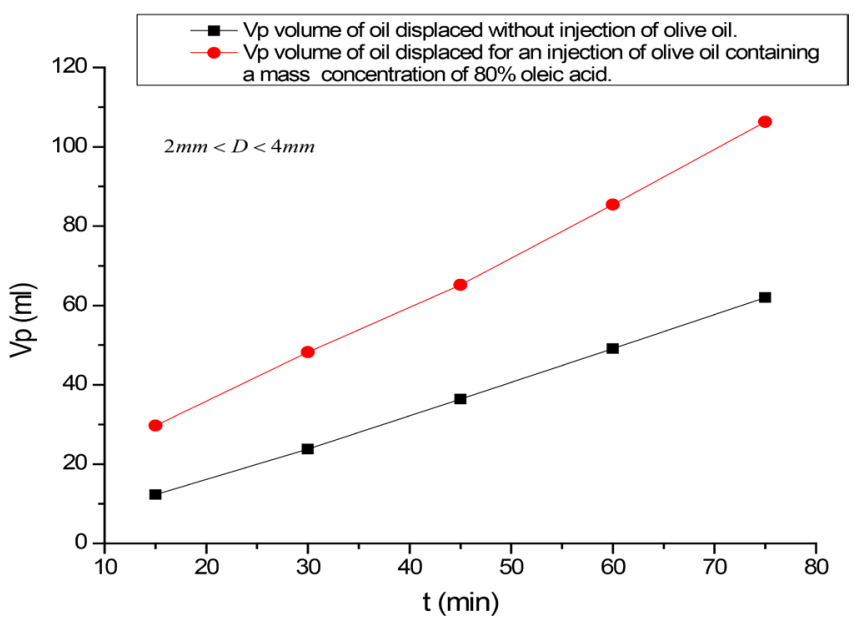

Figure 6. Vp volume of oil displaced for injection into the porous medium of olive oil containing a mass concentration of oleic acid of $80 \%$. 
We also note that the slope of this phase during tertiary recovery is more and more important according to the concentration of oleic acid contained in olive oil than secondary recovery, see the red Graphs $1-3$, which is logical if we consider that these are two-phase flows and that we are in the presence of surfactants which are positioned at the interface between water and oil to facilitate sweeping and reduce interfacial tensions. It has been experimentally found that yellow-colored oleic acid is positioned at the interface between water and petroleum, which is consistent according to its physicochemical properties and the numerical models, see Figure 7.

It has been found in the porous medium that the transient regime is quite long without the surfactants, unlike the use of oleic acid, the permanent regime of which was obtained with a relatively short time, see Figure 8 and Figure 9.

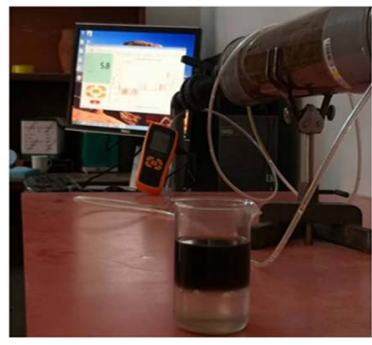

(a)

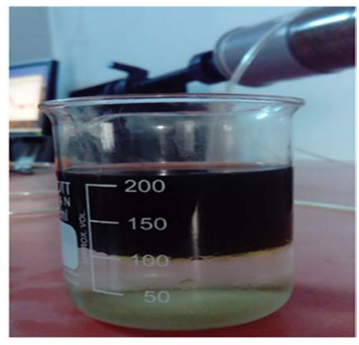

(b)

Figure 7. (a) experimental setup after saturation of the porous medium with crude oil and olive oil and (b) sample recovered after injection of water which shows the yellow oleic acid which is positioned at the interface between water and oil.
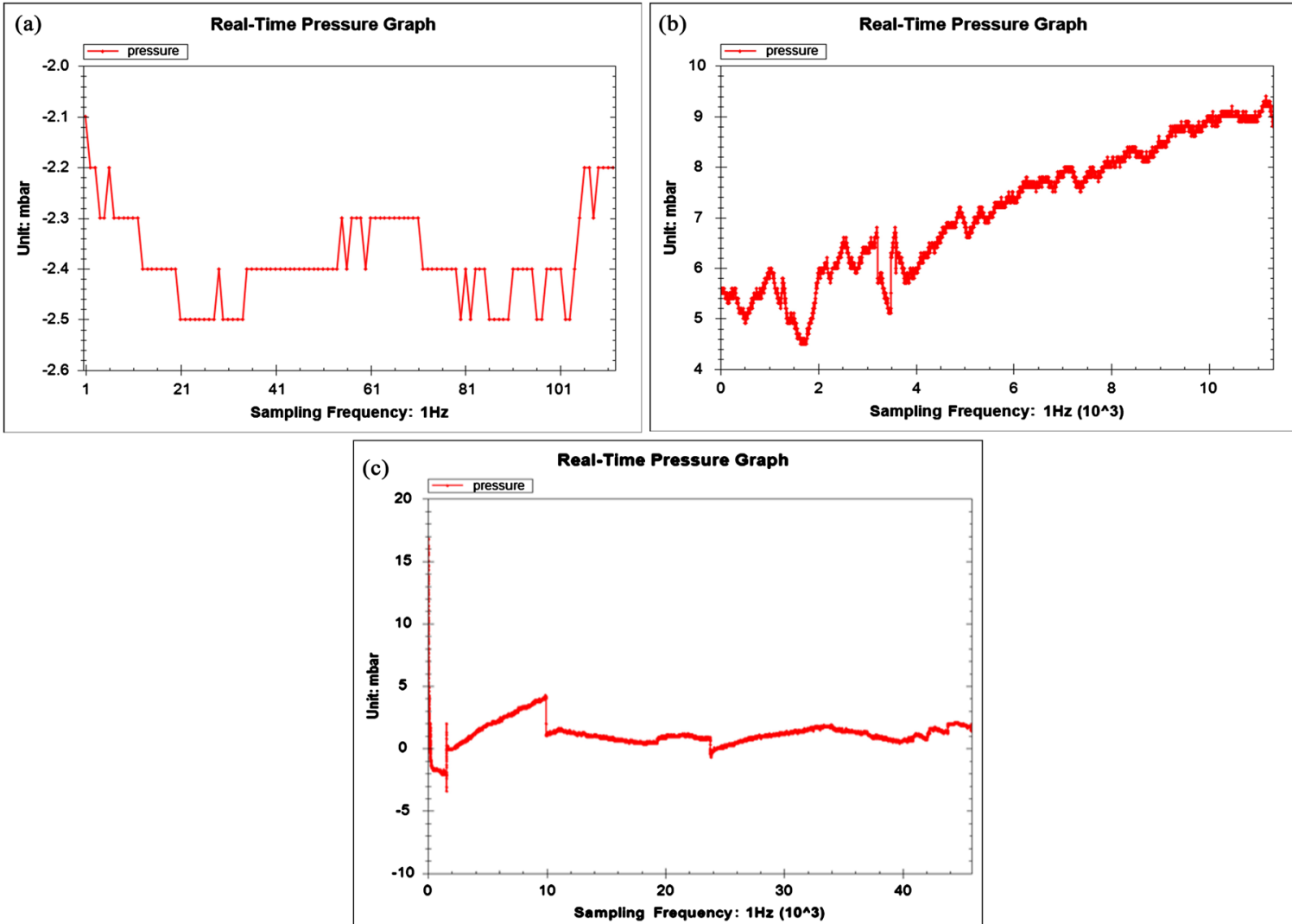

Figure 8. (a) and (b) Pressure loss under transient conditions for a short and long period, (c) Pressure loss under stable conditions for a long period without injecting surfactants into the porous medium. 


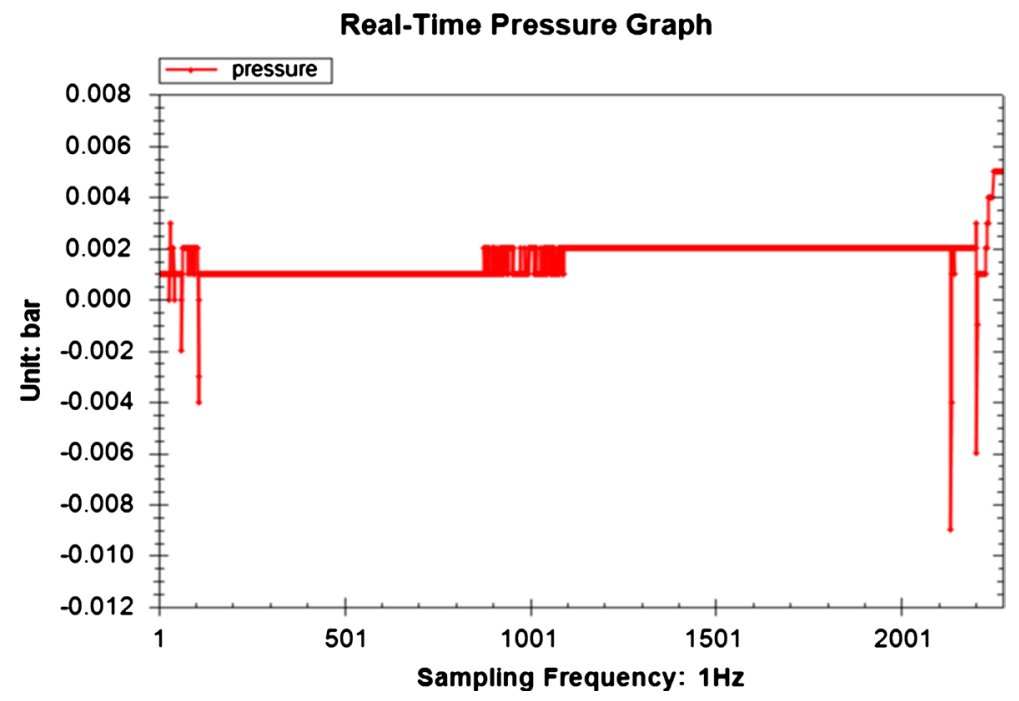

Figure 9. State of equilibrium established in a short time in the presence of surfactants in the medium.

\section{Conclusions and Perspective}

\subsection{Conclusions}

The existence of the difference in affinity of the hydrophilic part and the hydrophobic part of the oleic acid molecule, is at the origin of its self-organizing properties at the interface between water and petroleum (Figure 10).

These properties can lead to aggregates of different sizes and morphologies, as well as to the adsorption capacity at the interface, inducing a decrease in the surface tension of water caused by van der Waals interactions and the formation hydrogen bonds between water and the hydrophilic part of oleic acid.

When an amphiphile is dissolved in water, which is the case with oleic acid, the hydrophobic group destroys the structure of water at the interface between water and petroleum, which causes regular distortion and structuring of the molecules at the interface in order to exclude the hydrophobic parts of the water. During these two-phase flows in this porous medium, it has been observed that the volume of oil recovered increases with the mass concentration of oleic acid contained in olive oil.

Oleic acid therefore has an effect on the viscosity of the displacement fluid and the flow rate. Therefore, the viscosity of the displacement fluid plays an essential role in improving the improved oil recovery. Consequently, the surfactant solutions make it possible to reduce the viscosity of petroleum and increase the viscosity of water, which leads, when injected into the porous medium, to a reduction in instabilities at the interface between water and petroleum, the wettability of rock, to reduce the interfacial tension between oil/water and by mobilizing the drops of oil trapped by capillary effects towards production.

Depending on its physicochemical properties, oleic acid used as a surfactant is positioned at the interface between oil and water, which effectively displaces the residual oil trapped in the pores to increase production. Improved oil recovery 
(a)

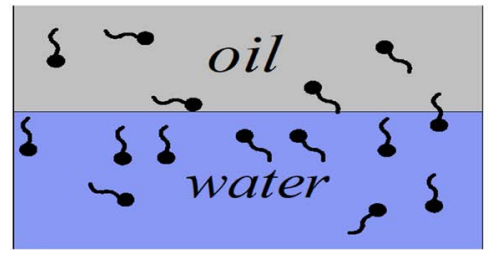

(b)

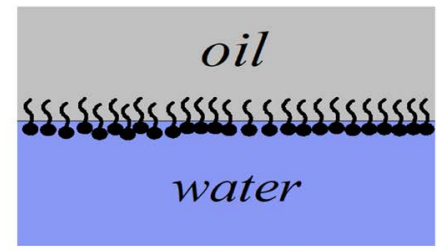

Figure 10. The oleic acid stabilizes at the interface between water and oil. (a) Transient regime in the presence of surfactants in the porous medium; (b) Steady state in the presence of surfactants in the porous medium.

techniques are more expensive than primary and secondary recovery methods, hence the choice used oleic acid as a surfactant, for example, which is cheaper and abundant in nature to improve the mobility of the oil. Speed between the injected fluid and the oil which remains trapped in the pores.

The injection into the porous medium of olive oil containing a mass concentration of oleic acid of $70 \%$ the volume of the oil recovered has increased. This increase in displaced oil is more and more marked during the injection of olive oil containing $80 \%$ oleic acid. Consequently, the physicochemical properties at the interface between petroleum and water are modified by oleic acid, lowering the viscosity of petroleum and increasing the viscosity of water, which facilitates the mobility of petroleum in the porous medium.

The physicochemical properties at the interface between petroleum and water are modified by oleic acid, lowering the viscosity of petroleum and increasing the viscosity of water, which facilitated the mobility of petroleum in the porous medium.

\subsection{Perspective}

Physico-chemical methods improve oil recovery and allow the production of oil in deposits by injecting surfactants acting on the different physicochemical parameters. We hope that this research work can help petroleum companies to improve the production of oil in deposits.

The analysis of the sampling recovered by new techniques will allow us in the next article to verify and validate the position of the oleic acid molecule at the water-oil interface compared to numerical models.

\section{Conflicts of Interest}

The authors declare no conflicts of interest regarding the publication of this paper.

\section{References}

[1] Shah, D.O. (2012) Improved Oil Recovery by Surfactant and Polymer Flooding. Elsevier, Amsterdam.

[2] Taylor, K.C. and Nasr-El-Din, H.A. (1998) Water-Soluble Hydrophobically Associating Polymers for Improved Oil Recovery: A Literature Review. Journal of Petroleum Science and Engineering, 19, 265-280. 
[3] Torsater, O., et al. (2012) Improved Oil Recovery by Nanofluids Flooding: An Experimental Study. SPE Kuwait International Petroleum Conference and Exhibition, Kuwait City, 10-12 December 2012, 9. https://doi.org/10.2118/163335-MS

[4] Pal, S., et al. (2018) Review of Surfactant-Assisted Chemical Enhanced Oil Recovery for Carbonate Reservoirs: Challenges and Future Perspectives. Petroleum Science, 15, 77-102. https://doi.org/10.1007/s12182-017-0198-6

[5] Vargo, J., Turner, J., Vergnani, B., Pitts, M.J., Wyatt, K., Surkalo, H. and Patterson, D. (2000) Alkaline-Surfactant/Polymer Flooding of the Cambridge Field. Journal of Petroleum Technology, 52, 48-49. https://doi.org/10.2118/55633-MS

[6] Meyers, J.J., Pitts, M.J. and Wyatt, K. (1992) Alkaline-Surfactant-Polymer Flood of the West Kiehl, Minnelusa Unit. 8th Symposium on Enhanced Oil Recovery (Proceedings), Tulsa, 22-24 April 1992, SPE 16474. https://doi.org/10.2118/24144-MS

[7] Clark, S.R., Pitts, M.J. and Smith, S.M. (1993) Design and Application of an Alka-Line-Surfactant-Polymer Recovery System for the West Kiehl Field. SPE Advanced Technology Series, 1, 172-177. https://doi.org/10.2118/17538-PA

[8] Gryglewicz, S., Piechocki, W. and Gryglewicz, G. (2003) Preparation of Polyol Esters Based on Vegetable and Animal Fats. Bioresource Technology, 87, 35-39. https://doi.org/10.1016/S0960-8524(02)00203-1

[9] Schmitt, V., Cattelet, C. and Leal-Calderon, F. (2004) Coarsening of Alkane-in-Water Emulsions Stabilized by Nonionic Poly(oxyethylene) Surfactants: The Role of Molecular Permeation and Coalescence. Langmuir, 20, 46-52. https://doi.org/10.1021/la034747p

[10] Olajire, A.A. (2014) Review of ASP EOR (Alkaline Surfactant Polymer Enhanced Oil Recovery) Technology in the Petroleum Industry: Prospects and Challenges. Energy, 77, 963-982. https://doi.org/10.1016/j.energy.2014.09.005

[11] Endo, H., et al. (2001) Effect of Amphiphilic Block Copolymers on the Structure and Phase Behavior of Oil-Water-Surfactant Mixtures. The Journal of Chemical Physics, 115, 580-600. https://doi.org/10.1063/1.1377881

[12] Davarpanah, A., Shirmohammadi, R. and Mirshekari, B. (2019) Experimental Evaluation of Polymer-Enhanced Foam Transportation on the Foam Stabilization in the Porous Media. International Journal of Environmental Science and Technology, 16, 8107-8116. https://doi.org/10.1007/s13762-019-02280-Z

[13] Kunieda, H. and Yamagata, M. (1993) Mixing of Nonionic Surfactants at Water-Oil Interfaces in Microemulsions. Langmuir, 9, 3345-3351.

https://doi.org/10.1021/la00036a005

[14] Shinoda, K., et al. (1981) Principles of Attaining Ultra-Low Interfacial Tension: The Role of Hydrophile-Lipophile-Balance of Surfactant at Oil/Water Interface. Colloids and Surfaces, 2, 301-314. https://doi.org/10.1016/0166-6622(81)80020-0

[15] Kamal, M.S., Hussein, I.A. and Sultan, A.S. (2017) Review on Surfactant Flooding: Phase Behavior, Retention, IFT, and Field Applications. Energy \& Fuels, 31, 7701-7720. https://doi.org/10.1021/acs.energyfuels.7b00353

[16] Menendez, J.A., et al. (2005) Oleic Acid, the Main Monounsaturated Fatty Acid of Olive Oil, Suppresses her-2/neu (erb b-2) Expression and Synergistically Enhances the Growth Inhibitory Effects of Trastuzumab (Herceptin ${ }^{\mathrm{Tm}}$ ) in Breast Cancer Cells with her-2/neu Oncogene Amplification. Annals of Oncology, 16, 359-371. https://doi.org/10.1093/annonc/mdi090

[17] Chauveteau, G., Tirrell, M. and Omari, A. (1984) Concentration Dependence of the Effective Viscosity of Polymer Solutions in Small Pores with Repulsive or Attractive Walls. Journal of Colloid and Interface Science, 100, 41-54. 
https://doi.org/10.1016/0021-9797(84)90410-7

[18] Candau, S. (2001) Linear Viscoelasticity of Salt-Free Wormlike Micellar Solutions. Colloids and Surfaces A: Physicochemical and Engineering Aspects, 183-185, 514. https://doi.org/10.1016/S0927-7757(01)00535-0

[19] Magid, L.J., Han, Z., Li, Z. and Butler, P.D. (2000) Tuning the Contour Lengths and Persistence Lengths of Cationic Micelles: The Role of Electrostatics and Specific Ion Binding. Journal of Physical Chemistry B, 104, 6717-6727. https://doi.org/10.1021/jp994477c

[20] Raghavan, S.R., Edlund, H. and Kaler, E.W. (2002) Cloud-Point Phenomena in Wormlike Micellar Systems Containing Cationic Surfactant and Salt. Langmuir, 18, 1056-1064. https://doi.org/10.1021/la011148e

[21] Lin, Z. (2001) Influence of Surfactant Concentration and Counterion to Surfactant Ratio on Rheology of Wormlike Micelles. Journal of Colloid and Interface Science, 239, 543-554. https://doi.org/10.1006/jcis.2001.7618 